\title{
Population Trends and the ESRC Centre for Population Change - working in partnership
}

\author{
Jane Falkingham \\ Director ESRC Centre for Population Change, University of Southampton
}

Following the successful themed edition of Population Trends in September 2010, it is with great pleasure that I accepted the invitation to be guest editor of a second themed edition this year. It is however with great regret that I do so with the knowledge that this is the last ever edition of Population Trends. Throughout my career Population Trends has been a valuable source of information on the latest research being conducted both within ONS and academia and will be much missed. The first edition, published in Autumn 1975, contained just four very brief articles on the life table, infant mortality, births and patterns of family formation and international migration, together covering the three components of population change. Over the years, both the scope and content of articles within Population Trends expanded as it became recognised as one of the leading journals in its field. It is fitting that this final edition is bumper in both size and content, containing articles from researchers working within the ESRC Research Centre for Population Change, ONS and elsewhere in academia and covering a broad range of topics reflecting the diversity of contemporary demographic and population related research.

The Centre for Population Change (CPC) is funded for five years by the ESRC and aims to improve our understanding of the key drivers and implications of population change within the UK. The Centre is a joint initiative between the University of Southampton and a consortium of Scottish Universities including St Andrews, Edinburgh, Strathclyde, Dundee and Stirling, in partnership with the Office for National Statistics (ONS) and the National Records of Scotland (NRS). A hallmark of the Centre's research is a focus on the dynamic interconnections between the different demographic processes and the implications for policy and the community in the context of an ageing society. Ranging from in-depth qualitative studies of the processes underlying individual demographic behaviour through to complex statistical and economic modelling, the Centre's research aims to enhance the evidence base both for improved population projections and for policy formulation. 
As was the case in 2010, the seven articles published here have been chosen to showcase both the range of research topics and the variety of datasets being used within the Centre. The first article by Dieter Demey, Ann Berrington, Maria Evandrou and Jane Falkingham uses data from the General Household Survey (GHS) for the period 1984 to 2007 to examine changes in the demographic and socio-economic circumstances of British men and women in mid-life. Mid-life, defined here as the period between ages 45 and 64, is an under-researched phase of the life course but with the ageing of the 1960s baby boomers, one that is going to take on greater significance. As the authors demonstrate, changes in the occurrence and timing of life events such as marriage and parenthood as well as increased longevity mean that mid-life has become more demographically complex, characterised by the continuing need to support adult offspring, ageing parents and marked by many becoming grandparents themselves. More people in mid-life, particularly men, are also likely to find themselves living alone.

The second article by Éva Beaujouan and Máire Ní Bhrolcháin presents an overview of trends in cohabitation and marriage in Britain since the 1970s, using a consistent set of retrospective histories from the Centre for Population Change GHS time series dataset (1979 to 2007). This new dataset allows the investigation of changes in partnership behaviour over the past four decades including detailed analysis of changes in the average age at marriage and cohabitation, the time spent in different types of partnership and the outcome of cohabitation and marriage five and ten years later. Their findings suggest that more cohabiting couples separate without marrying, and fewer marry, than two decades ago. Moreover, fewer people are now living with a married or cohabiting partner than in the recent past, both because of delayed entry into partnership and higher proportions separating - again highlighting the trend towards solo living at ages 40 and above.

The third article by Athina Vlachantoni, Richard Shaw, Rosalind Willis, Maria Evandrou, Jane Falkingham, and Rebekah Luff moves further up the life course, with a focus on 'Measuring unmet need for social care amongst older people'. Highly topical following the publication of the Dilnot Report in July 2011, the article explores the concept of 'unmet need' for support in relation to specific Activities of Daily Living (ADLs) and Instrumental Activities of Daily Living (IADLs), using data on the receipt of support (informal, formal state or formal paid) from the General Household Survey, the English Longitudinal Study of Ageing (ELSA) and the British Household Panel Survey (BHPS). The results highlight that different kinds of need tend to be supported by particular types of care. Importantly for policy makers, the paper also finds that there is a significant level of 'unmet need' for certain activities.

Over the past 12 months, of all the components of population change, migration has probably received the most attention from both policy makers and the popular press. Two articles illustrate the breadth of research within CPC in this area. The article by David McCollum and Allan Findlay presents new evidence on the recent trends in migration from the A8 'accession countries' to the UK during the period 2004 - 2010 using data from the recently discontinued Worker Registration Scheme. They investigate whether the volume and local geographies of A8 migration to the UK have changed in response to the recent recession and, if so, how the extent to which these changes have been related to geographical differences in the labour market. Chris Wilson and Lee Williamson then use a recently proposed measure, the overall replacement ratio or ORR, to assess the extent to which migration might offset declines in fertility and alter intergenerational replacement. Their results demonstrate that the UK as a whole can be seen to experience 
'replacement migration' as immigration compensates for fertility below the replacement level. However, the paper also highlights that the impact of migration differs radically in the different regions of the country.

Both of the papers on migration include a spatial dimension to their analysis. Previous researchers have shown that the results of statistical analysis may differ substantially according to the scale and pattern of the areal units used, giving rise to the modifiable areal unit problem (MAUP). The penultimate CPC paper by Robin Flowerdew illustrates the methodological work of the Centre, investigating 'How serious is the Modifiable Areal Unit Problem for analysis of English census data?'. He illustrates that in many cases the level of spatial disaggregation makes little or no difference to the results, but there are some variables where the MAUP effect is substantial. The paper also provides a useful set of recommendations for any analyst thinking of carrying out analysis of Census data to consider.

The final CPC paper by Éva Beaujouan, James Brown and Máire Ní Bhrolcháin is also methodological, presenting two new sets of weights applicable to the General Household Survey from 1979 to 2007 . One of these is for use with any general analysis of GHS topics and the second is designed for analyses of data collected in the Family Information section. The performance of the weights is assessed in estimating the Total Fertility Rate (TFR) from 1971-2007, an aggregate measure of fertility for which reliable figures are available at national level from vital registration statistics. The new CPC weights improve the GHS estimates, reducing bias both in the TFR and in age-specific fertility rates. 